410

The Open Dentistry Journal

RESEARCH ARTICLE

\title{
How to Sterilize 3D Printed Objects for Surgical Use? An Evaluation of the Volumetric Deformation of 3D-Printed Genioplasty Guide in PLA and PETG after Sterilization by Low-Temperature Hydrogen Peroxide Gas Plasma
}

\author{
Olivier Oth $^{1, *}$, César Dauchot $^{1}$, Maria Orellana ${ }^{1}$ and Régine Glineur ${ }^{1}$ \\ ${ }^{1}$ Department of Oral and Maxillofacial Surgery, Hôpital Erasme, Université Libre de Bruxelles, Route de Lennik 808, 1070, Brussels, Belgium
}

\begin{abstract}
:
Introduction:

In the present time, there is rapid development in the application of $3 \mathrm{D}$ printing technology in surgery. One of the challenges encountered by the surgeon is the sterilization of these $3 \mathrm{D}$-printed objects for use in the operating room.

\section{Materials and Methods:}

Forty-two identical cutting guides used for genioplasty were 3D-printed: twenty-one in Polylactic acid (PLA) and twenty-one in Polyethylene terephthalate glycol (PETG). The guides were CT scanned after printing. They were then sterilized with the low-temperature hydrogen peroxide

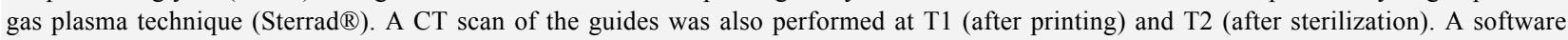
(Cloudcompare ${ }^{\circledR}$ ) was then used to accurately compare the volume of each guide at T0 (the initial computer-aided designed guide) vs T1 and T1 vs T2. Statistical analysis was then performed.

Results:

Although there are differences that are statistically significant for each series between T0 and T2 and T1 and T2 for both PLA and PETG, this had no impact on the clinical use of sterilized objects using hydrogen peroxide sterilization technique because these morphological differences were minimal at less than $0.2 \mathrm{~mm}$.

Conclusion:

Morphological deformations induced by the hydrogen peroxide sterilization are sub-millimeter and acceptable for surgical use. The hydrogen peroxide sterilization is, therefore, an alternative to avoid the deformation of 3D-printed objects made from PLA and PETG during conventional steam sterilization (autoclave). To the best of our knowledge, this is the first study regarding the morphologic deformation of 3D-printed objects in PLA and PETG after sterilization for medical use.
\end{abstract}

Keywords: 3D printing, CADCAM, Additive manufacturing, Fused deposition modelling, Maxillofacial surgery, Orthognathic surgery, Genioplasty, Polylactic acid, PLA, PETG, Polyethylene terephthalate glycol, Sterilization, Hydrogen peroxide gas plasma, Sterrad sterilization system.

\section{INTRODUCTION}

In the present time, there is a surge in the use of 3D printing technology in surgery, especially in the area of craniomaxillofacial surgery. 3D printing, also known as rapid prototyping and/or additive manufacturing, is becoming a significant tool in maxillo facial surgery [1].

\footnotetext{
* Address correspondence to this author at the Department of Oral and Maxillofacial Surgery, Hôpital Erasme, Université Libre de Bruxelles, Route de Lennik 808, 1070, Brussels, Belgium: Tel: +32/2.555.31.11;

E-mail: oth.olivier@gmail.com
}

Examples of applications of 3D printing in cranio-maxillofacial surgery are: anatomical models for teaching purposes, intraoperative visualization of the anatomical structures, anatomical models using the mirroring technique for pre-bending of osteosynthesis material, and surgical guides used intra operatively in implantology, orthognathic surgery, oncologic, and reconstructive maxillofacial surgery.

There are two possibilities for a surgeon to use 3D printing technologies in practice: Either to call upon outside firms to deal with design and 3D printing, or to understand the design 
and 3D printing within its hospital institution, aka "in-house printing", or "point of care manufacturing". In both cases, the surgeon is faced with the problem of sterilization of 3D-printed objects, which is mandatory for their use in the operating room.

Sterilization can be performed by 2 types of recognized methods [2]: 1) Thermal sterilization by dry heat or steam, aka moist heat sterilization or autoclave; 2) Low-temperature sterilization: chemical (with ethylene oxide or hydrogen peroxide for example), or with radiation (ionizing or UV).

Our in-house 3D-printing medical department used a Fused Deposition Modeling (FDM) 3D-printer. Thermoplastic polymers are the most ideal printing materials for additive manufacturing processes, such as FDM due to their low melting temperature [3]. The problem with plastic biomaterials such as Polylactic Acid (PLA) and Polyethylene Terephthalate Glycol (PETG) is that they are sensitive to conventional thermal steam sterilization techniques, including the temperature of 121 degree Celsius and above with high rates of humidity). These materials are deformed with this type of sterilization.

Thermal sterilization by dry heat is no longer authorized in the European Union. Ultraviolet light sterilization is a method of sterilization based on the sensitivity of microorganisms to get exposed to low wavelengths of ultraviolet light. This method is used in research laboratories to prepare sterile worktops, for the preservation of food, or the purification of air or water. Ionizing radiation is used by medical equipment companies and food decontamination [4]. The materials are packaged and stored in a shipping container that is gamma irradiated. Therefore, this method is not suitable for a $3 \mathrm{D}$ printing laboratory in a healthcare institute.

Ethylene oxide leads to changes in the polymer structures, provokes molecular weight loss and creates a toxic deposit on the surface of the object. Ethylene oxide sterilization is thus not recommended for PLA or PETG [5].

For all these reasons, the study was focused on hydrogen peroxide low-temperature sterilization. This sterilization technique exploits the synergism between peroxide and low temperature gas plasma to rapidly destroy microorganisms [6]. At the completion of this sterilization process, no toxic residues remain on the sterilized items. The technology is known to be particularly suited to the sterilization of heat and moisture sensitive instruments since process temperatures do not exceed about $50^{\circ} \mathrm{C}$ and sterilization occurs in a low moisture environment. The efficacy of the process has been demonstrated against a broad spectrum of microorganisms. This method has advantages over ethylene oxide including sterilization of safety, ease of maintenance and no requirement for aeration time [7].

Many articles can be found related to the applications of $3 \mathrm{D}$-printed devices in medicine, yet very few of them fully describe the technique of disinfection/sterilization. Only two articles were found focusing on the sterilization of 3D printed objects $[8,9]$.

The referenced object chosen for this study is a cutting guide used in orthognathic surgery to perform genioplasty. Genioplasty is a widely used surgical technique to correct chin deformity. It consists of an osteotomy of the inferior border of the mandible allowing movement of the chin in three dimensions and positioning it in its new desired position [10]. This guide can aid the surgeon in not touching the surrounding noble anatomical structures (dental roots, inferior alveolar nerve) and guide his surgical gesture as he performs this osteotomy.

The aim of this study was to investigate the morphological effect of the hydrogen peroxide low-temperature sterilization on surgical objects that are 3D-printed in PLA and PETG. The reference object chosen for this study is a cutting-edge guide used in orthognathic surgery to perform genioplasty. Genioplasty is a widely used surgical technique to correct chin deformity.

\section{METHODS}

To investigate the effect of hydrogen peroxide, lowtemperature sterilization on surgical objects 3D-printed in PLA and PETG, the following study was designed.

\subsection{D Printing Process}

The surgical guides are designed in the maxillofacial department, with a protocol developed and optimized for several years. Two series of 21 identical guides were printed: one series was printed in PLA (makerbot ${ }^{\circledR}$ PLA filament 1.75 $\mathrm{mm}$ ), and the other in PETG (taulman ${ }^{\circledR} 3$ D guidel!ne ${ }^{\circledR}$ filament $1.75 \mathrm{~mm})$.

The 3D printer model is a Replicator $+{ }^{\circledR}$ (Makerbot Industries $^{\circledR}$, New York, USA) operating on the principle of additive technology, Fused Deposit Modelling. Table 1 shows the parameters of the 3D-printer used for each material. Table 2 shows the physical properties of the solidified form of PLA and PETG.

Table 1. Range of process parameters of the 3D printer for PLA and PETG.

\begin{tabular}{|c|c|}
\hline Parameters Range for PLA & Parameters Range for PETG \\
\hline Layer thickness $(\mathrm{mm}) 0.1 \mathrm{~mm}$ & Layer thickness $(\mathrm{mm}) 0.3 \mathrm{~mm}$ \\
\hline Nozzle diameter $(\mathrm{mm}) 0,5 \mathrm{~mm}$ & Nozzle diameter $(\mathrm{mm}) 0,5 \mathrm{~mm}$ \\
\hline Part Bed temperature $\left({ }^{\circ} \mathrm{C}\right)$ not heated room temperature $(15-25)$ & Part Bed temperature $\left({ }^{\circ} \mathrm{C}\right)$ not heated room temperature $(15-25)$ \\
\hline Extruder head speed $150 \mathrm{~mm} / \mathrm{sec}$ & Extruder head speed $150 \mathrm{~mm} / \mathrm{sec}$ \\
\hline Temperature of extruder $\left({ }^{\circ} \mathrm{C}\right) 215$ & Temperature of extruder $\left({ }^{\circ} \mathrm{C}\right) 215$ \\
\hline
\end{tabular}


Table 2. Physical properties of solidified PLA and PETG.

\begin{tabular}{|c|c|}
\hline Parameters Value of solidified PLA & Parameters Value of solidified PETG \\
\hline Grade $4043 \mathrm{D}$ & Grade not available \\
\hline Density $(\mathrm{g} / \mathrm{cm} 3) 1.24$ & Density $(\mathrm{g} / \mathrm{cm} 3) 1.27$ \\
\hline Glass Transition Temperature $\left({ }^{\circ} \mathrm{C}\right) 60$ & Glass Transition Temperature $\left({ }^{\circ} \mathrm{C}\right) 77$ \\
\hline Melting point $\left({ }^{\circ} \mathrm{C}\right) 160$ & Melting point $\left({ }^{\circ} \mathrm{C}\right) 100$ \\
\hline
\end{tabular}

\subsection{Sterilization Process}

STERRAD $^{\circledR}$ 100S (Johnson \& Johnson ${ }^{\circledR}$ company), a lowtemperature hydrogen peroxide sterilizer, with one short cycle of 50 minutes with temperature always lower than $55^{\circ} \mathrm{C}$ was used to sterilize the guides.

\subsection{Comparison and Validation Process: Morphological Analysis}

The morphology of the guide was compared 3 times: $\mathrm{T} 0=$ the guide computer-designed in $3 \mathrm{D}$ before $3 \mathrm{D}$ printing (STL file); $\mathrm{T} 1=$ the guide after $3 \mathrm{D}$ printing and before sterilization; $\mathrm{T} 2=$ the guide after $3 \mathrm{D}$ printing and after low-temperature hydrogen peroxide sterilization.

Before sterilization (T1), each series of guides in PLA and PETG were scanned with a CT-scanner using a high-resolution protocol with the following acquisition settings; system: SOMATOM Emotion 16, tube current: $130 \mathrm{mAs}$, gray-scale: 16 bits, potential: $130 \mathrm{kV}$, scan time $35 \mathrm{~s}$, voxel size: $0.01 \mathrm{~mm}^{3}$ $(0.24 \mathrm{~mm} \times 0.24 \mathrm{~mm} \times 0.20 \mathrm{~mm})$.

After sterilization (T2), each series was again scanned with the same CT-scanner and with the same acquisition settings.

The DICOM images were exported and 3D Slicer $^{\circledR}$ software was used to segment the guide and create STL files (the file extension used in 3D printing). Blender ${ }^{\circledR}$ software was then used to isolate each guide of both series.
To compare the morphology of the guides, Cloud Compare $^{\circledR}$ program was used. The principle of this software is to decompose an object, into a number (n) of points (voxel points) and then compare the deviation of the points of the reference guide with respect to the compared guide. 3D designed reference guide (T0) was compared with the sterilized guide (T2) and the printed non-sterilized guide (T1) with the sterilized guide (T2) (Figs. 1-4).

\subsection{Statistical Analysis}

Once the data was collected, Student t-paired tests were used to evaluate the differences in mean distances of the reference $3 \mathrm{D}$-designed guide $(\mathrm{t} 0)$, and the post sterilization guide (t2) and printed guide (t1) and sterilized guide (t2). Random factor ANOVAs were used to test the differences in morphometric means between 21 PLA guides and 21 PETG guides. A $p$-value of less than $5 \%$ was considered significant. Statistical analyses were performed with the $\mathrm{R}$ software (version 3.5.1).

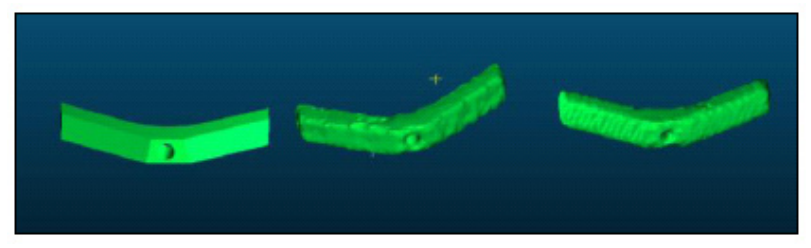

Fig. (1). (from left to right): Genioplasty guide designed in 3D (T0) 3D-printed guide non-sterilized (T1) - Guide after sterilization (T2).

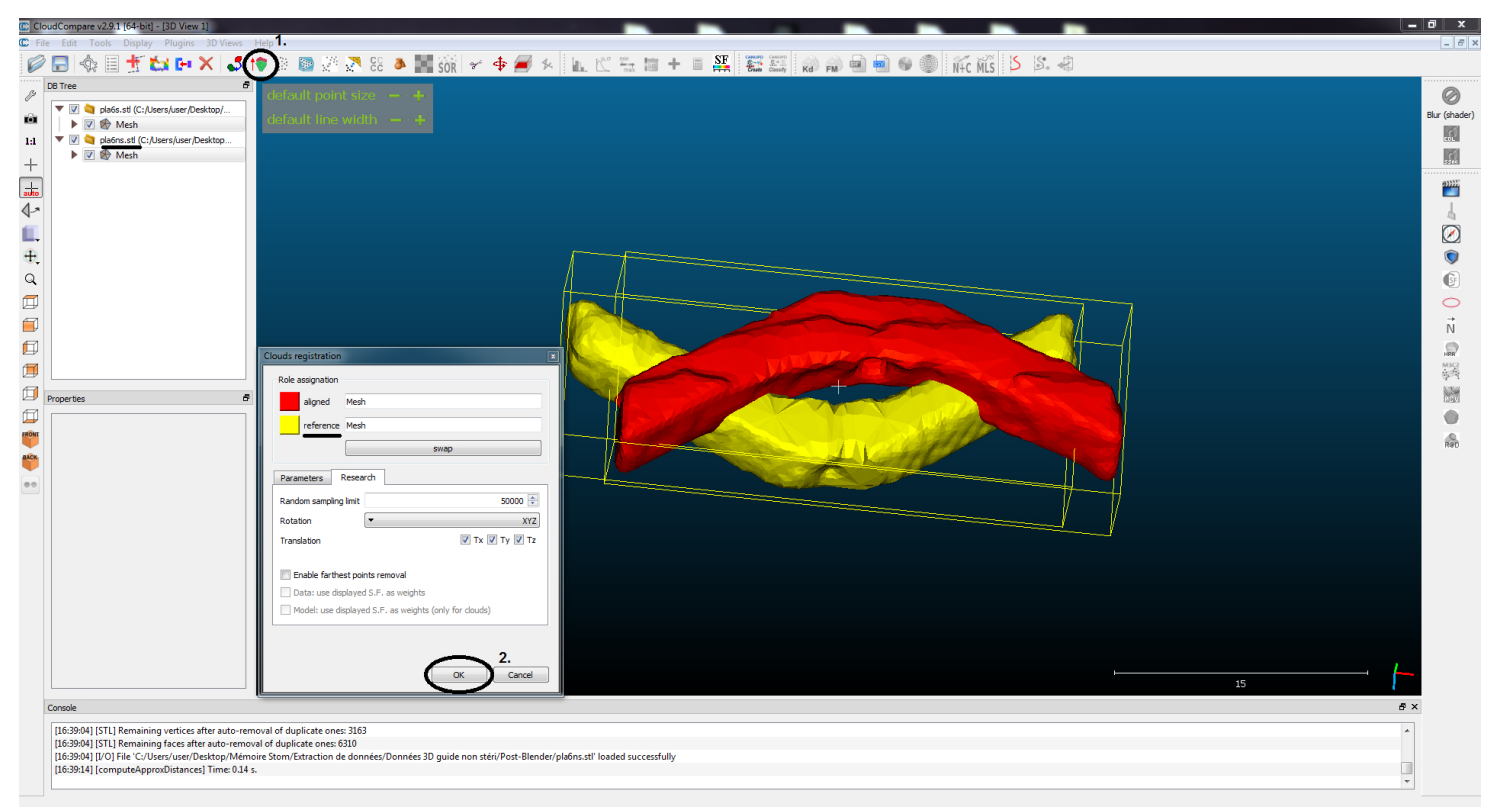

Fig. (2). Process of alignment of two scanned guide with the software Cloudcompare®. 


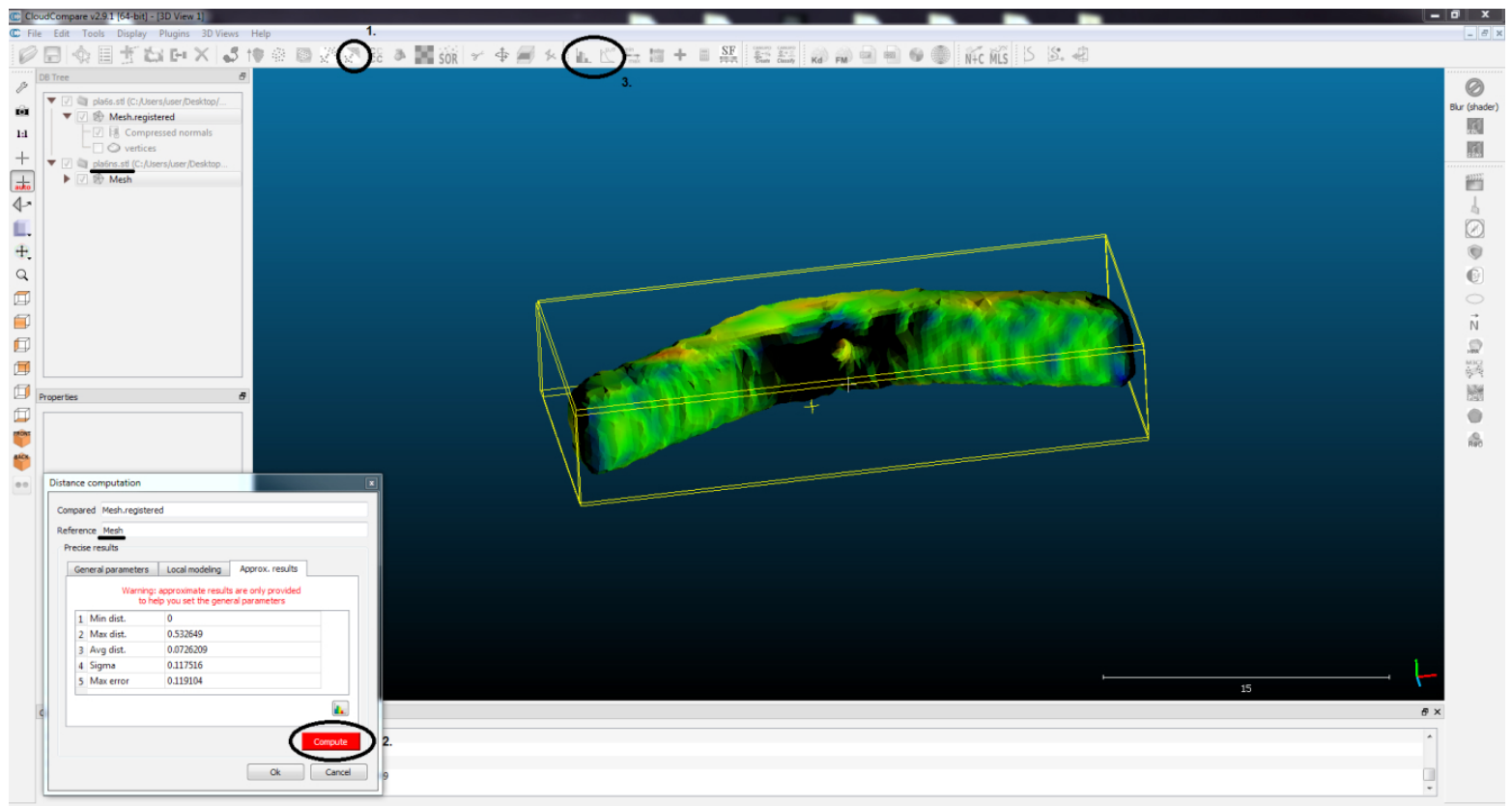

Fig. (3). Comparison of 2 guides via the $\mathrm{C} 2 \mathrm{M}$ function and extraction of the comparative data.

\section{RESULTS}

\subsection{PLA T0 - T2 (Reference 3D-Designed Guide - Sterilized Guide)}

18 out of the 21 guides have a significant average difference after the effect of printing and sterilization. In this series, the largest difference in average is $0.147 \mathrm{~mm}$ between the points of the guide. The ANOVA shows a significant average difference between the guides (Table 3 ).

\subsection{PLA T1 - T2 (Printed Guide - Sterilized Guide)}

19 out of the 21 guides have a significant average difference after the effect of sterilization. In this series, the largest difference in average is $0.1887 \mathrm{~mm}$ between the points of the guide. The ANOVA shows a significant average difference between the guides (Table 4).

\subsection{PETG T0-T2 (Reference 3D-Designed Guide-Sterilized $\underline{\text { Guide) }}$}

Only 1 out of the 21 guides do not have a significant average difference after the effect of printing and sterilization. In this series, the largest difference in average is $0.1887 \mathrm{~mm}$ between the points of the guide. The ANOVA shows a significant average difference between the guides (Table $\mathbf{5}$ ).

\subsection{PETG T1-T2 (Printed Guide-Sterilized Guide)}

21 guides have a significant average difference after the effect of printing. The largest difference in average is 0.0976 $\mathrm{mm}$ (Table 6).

\section{Gauss: mean $=0.024261 /$ std. $. d e v .=0.150409$ [66 classes $]$}

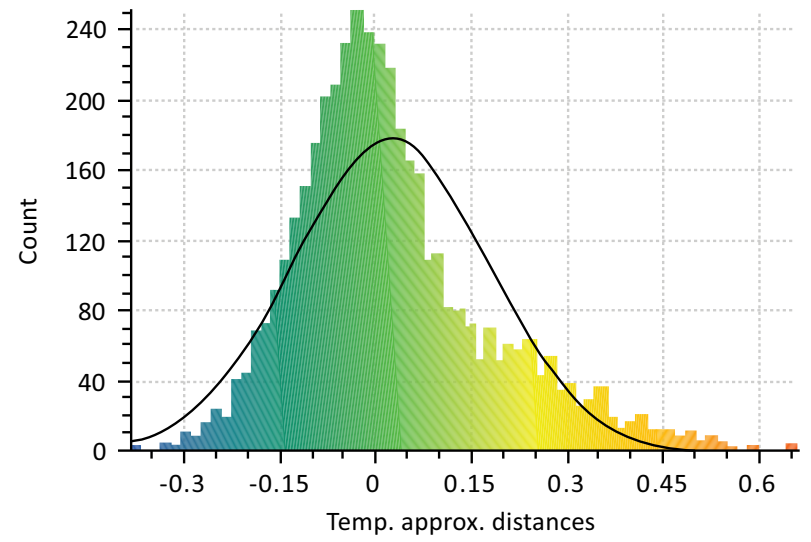

Fig. (4). Example of histogram and Gauss curve of the deviation of the points of one guide at T2 compared to the referenced object (guide at T0) obtained with CloudCompare ${ }^{\circledR}$. 
Table 3. PLA T0 - T2 (reference 3D-designed guide - sterilized guide).

\begin{tabular}{|c|c|c|c|c|c|c|c|}
\hline $\begin{array}{l}\text { Guide } \\
\text { ID }\end{array}$ & $\mathrm{n}$ & $\begin{array}{c}\text { Mean difference } \\
\text { t0-t2 }\end{array}$ & SD & $P$-value* & Lower $95 \%$ CI & $\begin{array}{c}\text { Upper } 95 \% \\
\text { CI }\end{array}$ & $P$-value** \\
\hline 1 & 4001 & 0,113 & 0,338 & $<0.001$ & 0,1035 & 0,1243 & \multirow{21}{*}{$<0.001$} \\
\hline 2 & 4033 & 0,147 & 0,218 & $<0.001$ & 0,1402 & 0,1536 & \\
\hline 3 & 4350 & 0,094 & 0,369 & $<0.001$ & 0,0845 & 0,1063 & \\
\hline 4 & 4097 & 0,126 & 0,298 & $<0.001$ & 0,1184 & 0,1366 & \\
\hline 5 & 4178 & 0,096 & 0,379 & $<0.001$ & 0,0870 & 0,1099 & \\
\hline 6 & 4240 & 0,058 & 0,440 & $<0.001$ & 0,0472 & 0,0736 & \\
\hline 7 & 4186 & 0,123 & 0,338 & $<0.001$ & 0,1156 & 0,1360 & \\
\hline 8 & 4177 & 0,068 & 0,424 & $<0.001$ & 0,0574 & 0,0830 & \\
\hline 9 & 4122 & 0,115 & 0,327 & $<0.001$ & 0,1062 & 0,1261 & \\
\hline 10 & 4307 & 0,111 & 0,359 & $<0.001$ & 0,1015 & 0,1229 & \\
\hline 11 & 4501 & 0,118 & 0,374 & $<0.001$ & 0,1081 & 0,1299 & \\
\hline 12 & 4203 & 0,101 & 0,346 & $<0.001$ & 0,0934 & 0,1142 & \\
\hline 13 & 4617 & 0,041 & 0,480 & $<0.001$ & 0,0282 & 0,0558 & \\
\hline 14 & 4323 & 0,077 & 0,421 & $<0.001$ & 0,0652 & 0,0902 & \\
\hline 15 & 4452 & $-0,015$ & 0,475 & 0,088 & $-0,0260$ & 0,0018 & \\
\hline 16 & 4360 & $-0,007$ & 0,484 & 0,435 & $-0,0200$ & 0,0086 & \\
\hline 17 & 4386 & $-0,009$ & 0,489 & 0,342 & $-0,0214$ & 0,0074 & \\
\hline 18 & 4134 & 0,127 & 0,330 & $<0.001$ & 0,1188 & 0,1388 & \\
\hline 19 & 4252 & 0,099 & 0,400 & $<0.001$ & 0,0887 & 0,1127 & \\
\hline 20 & 4187 & 0,132 & 0,330 & $<0.001$ & 0,1250 & 0,1449 & \\
\hline 21 & 4107 & 0,135 & 0,310 & $<0.001$ & 0,1263 & 0,1452 & \\
\hline
\end{tabular}

*Paired t-test; **One way fixed factor ANOVA

Table 4. PLA T0 - T2 (reference 3D-designed guide - sterilized guide).

\begin{tabular}{|c|c|c|c|c|c|c|c|}
\hline $\begin{array}{l}\text { Guide } \\
\text { ID }\end{array}$ & $\mathrm{N}$ & $\begin{array}{c}\text { Mean difference } \\
\text { t1-t2 }\end{array}$ & SD & $P$-value* & Lower 95\% CI & Upper $95 \%$ CI & $P$-value** \\
\hline 1 & 4001 & 0,1887 & 0,1546 & $<0.001$ & 0,184 & 0,194 & \multirow{21}{*}{$<0.001$} \\
\hline 2 & 4033 & 0,0047 & 0,1360 & 0,026 & 0,001 & 0,009 & \\
\hline 3 & 4350 & 0,0255 & 0,1416 & $<0.001$ & 0,022 & 0,030 & \\
\hline 4 & 4097 & 0,0014 & 0,1335 & 0,366 & $-0,002$ & 0,006 & \\
\hline 5 & 4178 & 0,0341 & 0,1411 & $<0.001$ & 0,031 & 0,039 & \\
\hline 6 & 4240 & 0,0242 & 0,1505 & $<0.001$ & 0,020 & 0,029 & \\
\hline 7 & 4186 & 0,0221 & 0,1451 & $<0.001$ & 0,019 & 0,028 & \\
\hline 8 & 4177 & 0,0307 & 0,1515 & $<0.001$ & 0,027 & 0,036 & \\
\hline 9 & 4122 & 0,0296 & 0,1408 & $<0.001$ & 0,026 & 0,035 & \\
\hline 10 & 4307 & 0,0161 & 0,1441 & $<0.001$ & 0,012 & 0,021 & \\
\hline 11 & 4501 & 0,0147 & 0,1387 & $<0.001$ & 0,011 & 0,019 & \\
\hline 12 & 4203 & 0,0051 & 0,1326 & 0,003 & 0,002 & 0,010 & \\
\hline 13 & 4617 & 0,0476 & 0,1581 & $<0.001$ & 0,043 & 0,053 & \\
\hline 14 & 4323 & 0,0021 & 0,1410 & 0,2463 & $-0,002$ & 0,007 & \\
\hline 15 & 4452 & $-0,0052$ & 0,1472 & 0,045 & $-0,0001$ & $-0,009$ & \\
\hline 16 & 4360 & 0,0220 & 0,1379 & $<0.001$ & 0,018 & 0,026 & \\
\hline 17 & 4386 & 0,0250 & 0,1422 & $<0.001$ & 0,021 & 0,030 & \\
\hline 18 & 4134 & 0,0140 & 0,1427 & $<0.001$ & 0,010 & 0,019 & \\
\hline 19 & 4252 & 0,0153 & 0,1516 & $<0.001$ & 0,011 & 0,020 & \\
\hline 20 & 4187 & 0,0349 & 0,1417 & $<0.001$ & 0,032 & 0,040 & \\
\hline 21 & 4107 & 0,0039 & 0,1426 & 0,047 & 0,0001 & 0,0087 & \\
\hline
\end{tabular}

*Paired t-test; **One way fixed factor ANOVA 
Table 5. PETG T0-T2 (reference 3D-designed guide - sterilized guide).

\begin{tabular}{|c|c|c|c|c|c|c|c|}
\hline $\begin{array}{l}\text { Guide } \\
\text { ID }\end{array}$ & $\mathrm{N}$ & $\begin{array}{c}\text { Mean difference } \\
\text { t0-t2 }\end{array}$ & DS & Lower 95\% CI & Upper $95 \%$ CI & $P$-value* & $P$-value** \\
\hline 1 & 4130 & 0,1980 & 0,2660 & 0,1911 & 0,2073 & $<0.001$ & \multirow{21}{*}{$<0.001$} \\
\hline 2 & 4156 & 0,0039 & 0,4283 & $-0,0070$ & 0,0189 & 0,3693 & \\
\hline 3 & 4277 & 0,1449 & 0,2787 & 0,1373 & 0,1539 & $<0.001$ & \\
\hline 4 & 5208 & 0,1971 & 0,2566 & 0,1887 & 0,2026 & $<0.001$ & \\
\hline 5 & 4130 & 0,1837 & 0,2570 & 0,1771 & 0,1927 & $<0.001$ & \\
\hline 6 & 4092 & 0,1781 & 0,2659 & 0,1709 & 0,1871 & $<0.001$ & \\
\hline 7 & 4114 & 0,1752 & 0,2488 & 0,1688 & 0,1839 & $<0.001$ & \\
\hline 8 & 4336 & 0,1125 & 0,3221 & 0,1040 & 0,1231 & $<0.001$ & \\
\hline 9 & 4197 & 0,1576 & 0,3322 & 0,1499 & 0,1699 & $<0.001$ & \\
\hline 10 & 4132 & 0,1863 & 0,2194 & 0,1806 & 0,1939 & $<0.001$ & \\
\hline 11 & 4165 & 0,1774 & 0,2715 & 0,1709 & 0,1874 & $<0.001$ & \\
\hline 12 & 4196 & 0,1648 & 0,2873 & 0,1582 & 0,1755 & $<0.001$ & \\
\hline 13 & 4512 & 0,1890 & 0,1724 & 0,1845 & 0,1945 & $<0.001$ & \\
\hline 14 & 4372 & 0,1782 & 0,2151 & 0,1726 & 0,1853 & $<0.001$ & \\
\hline 15 & 4216 & 0,1615 & 0,3124 & 0,1535 & 0,1723 & $<0.001$ & \\
\hline 16 & 4102 & 0,1890 & 0,2225 & 0,1831 & 0,1966 & $<0.001$ & \\
\hline 17 & 4193 & 0,1681 & 0,3056 & 0,1611 & 0,1796 & $<0.001$ & \\
\hline 18 & 4081 & 0,1722 & 0,2564 & 0,1649 & 0,1806 & $<0.001$ & \\
\hline 19 & 4133 & 0,1448 & 0,3218 & 0,1365 & 0,1560 & $<0.001$ & \\
\hline 20 & 4115 & 0,1684 & 0,2730 & 0,1614 & 0,1780 & $<0.001$ & \\
\hline 21 & 4113 & 0,1717 & 0,2667 & 0,1650 & 0,1812 & $<0.001$ & \\
\hline
\end{tabular}

*Paired t-test; **One way fixed factor ANOVA

Table 6. PETG T0-T2 (reference 3D-designed guide - sterilized guide).

\begin{tabular}{|c|c|c|c|c|c|c|c|}
\hline $\begin{array}{l}\text { Guide } \\
\text { ID }\end{array}$ & $\mathrm{N}$ & $\begin{array}{c}\text { Mean difference } \\
\text { t1-t2 }\end{array}$ & DS & Lower 95\% CI & Upper 95\% CI & $P$-value* & $P$-value** \\
\hline 1 & 4130 & 0,1055 & 0,1299 & 0,103 & 0,111 & $<0.001$ & \multirow{21}{*}{$<0.001$} \\
\hline 2 & 4156 & $-0,0116$ & 0,1485 & $-0,015$ & $-0,006$ & $<0.001$ & \\
\hline 3 & 4277 & 0,0352 & 0,1427 & 0,031 & 0,040 & $<0.001$ & \\
\hline 4 & 5208 & 0,0846 & 0,1306 & 0,080 & 0,087 & $<0.001$ & \\
\hline 5 & 4130 & 0,0727 & 0,1367 & 0,069 & 0,078 & $<0.001$ & \\
\hline 6 & 4092 & 0,0576 & 0,1329 & 0,054 & 0,062 & $<0.001$ & \\
\hline 7 & 4114 & 0,0651 & 0,1381 & 0,062 & 0,070 & $<0.001$ & \\
\hline 8 & 4336 & 0,0088 & 0,1297 & 0,005 & 0,013 & $<0.001$ & \\
\hline 9 & 4197 & 0,0672 & 0,1348 & 0,064 & 0,072 & $<0.001$ & \\
\hline 10 & 4132 & 0,0798 & 0,1235 & 0,077 & 0,084 & $<0.001$ & \\
\hline 11 & 4165 & 0,0500 & 0,1411 & 0,047 & 0,055 & $<0.001$ & \\
\hline 12 & 4196 & 0,0541 & 0,1414 & 0,051 & 0,059 & $<0.001$ & \\
\hline 13 & 4512 & 0,0868 & 0,1192 & 0,084 & 0,091 & $<0.001$ & \\
\hline 14 & 4372 & 0,0582 & 0,1251 & 0,055 & 0,062 & $<0.001$ & \\
\hline 15 & 4216 & 0,0827 & 0,1399 & 0,079 & 0,088 & $<0.001$ & \\
\hline 16 & 4102 & 0,0906 & 0,1333 & 0,087 & 0,095 & $<0.001$ & \\
\hline 17 & 4193 & 0,0976 & 0,1420 & 0,094 & 0,103 & $<0.001$ & \\
\hline 18 & 4081 & 0,0743 & 0,1240 & 0,071 & 0,078 & $<0.001$ & \\
\hline 19 & 4133 & 0,0808 & 0,1371 & 0,077 & 0,086 & $<0.001$ & \\
\hline 20 & 4115 & 0,0776 & 0,1417 & 0,074 & 0,083 & $<0.001$ & \\
\hline 21 & 4113 & 0,0767 & 0,1376 & 0,073 & 0,082 & $<0.001$ & \\
\hline
\end{tabular}

*Paired t-test; **One way fixed factor ANOVA 


\section{DISCUSSION}

Very few papers have studied the sterilization of 3Dprinted objects. Kozakiewicz has studied the effect of sterilization on paper-based 3D-printed solids [9]. Shaheen has studied the effect of sterilization of objects printed with the PolyJet technology (Stratasys, Eden Prairie, MN USA). Limit to disinfection of the 3D-printed objects should be avoided in all cases [8].

According to Bathia and Ramadurai [11], the material released from an FDM 3D-printer is sterile since it leaves the extruder at $220^{\circ} \mathrm{C}$ (well above the $121^{\circ} \mathrm{C}$ recommended for steam sterilization). But contamination of the printing plate is always possible and a totally sterile manipulation of the object from $3 \mathrm{D}$ printing to the operating room cannot be guaranteed. The use of a conventional sterilization technique and the preservation of the sterilized object in a package provided for this purpose are therefore necessary.

PLA and PETG are very common bio-materials in 3Ddesktop FDM-printer. Those materials do not bear high temperature. This guide in PLA and PETG melted under a short cycle of 5 minutes under $121^{\circ} \mathrm{C}$ with thermal steam sterilization, making the use of autoclave impossible. This is the reason why this technique of sterilization is not recommended. But this finding is inconsistent with the study of Boursier et al. [12] who concluded that PLA printed-objects with FDM 3D printer can be sterilized with an autoclave. Boursier et al. scanned a cat's femur after dissection, printed it, sterilized it and compared its deformation with handly measurements. This inconsistency could be explained by the fact that Boursier et al. use a different 3D printer and a PLA from another brand. PLA is a polymer composed of L-lactide and Dlactide chains. The thermal and mechanical properties of PLA depend on the ratio and distribution of L- and D-LA in the polymer chains. The melting temperatures and the transition glass temperature could thus vary from one brand to another. Because the temperature of hydrogen peroxide sterilization always stays lower than $55^{\circ} \mathrm{C}$, this technique can be applied to all subtypes of PLA.

No study about sterilization of PETG was found in the literature. The use of PETG (taulman ${ }^{\circledR} 3 \mathrm{D}$ guidel!ne ${ }^{\circledR}$ filament $1.75 \mathrm{~mm}$ ) for additive manufacturing in medical use should be preferred because of its proven biocompatibility in accordance with the industrial standard, its European ISO10993 certification and its American FDA-approval [13].

The other sterilization techniques have significant disadvantages. Thermal sterilization by dry heat is currently prohibited in the hospitals of the European Union (because of inactivity on prions). Radiation sterilization is used in the food and medical device industry and its use is not suitable for hospitals. Ethylene oxide should be avoided because it leads to changes in the polymer structures, provokes molecular weight loss and creates a toxic deposit on the surface of the object. In comparison, with the hydrogen peroxide low-temperature sterilization, no toxic residues remain on the sterilized items. This technique is effective, safe and does not require aeration time compared to ethylene oxide [7].
Regarding the results in morphology variations, although there are differences that are statistically significant for each series between $\mathrm{T} 0$ and $\mathrm{T} 2$ and $\mathrm{T} 1$ and $\mathrm{T} 2$ for both PLA and PETG, this has no impact on the clinical use of sterilized objects using hydrogen peroxide sterilization technology. Indeed, these morphological differences are minimal and less than $0.2 \mathrm{~mm}$. Furthermore, these differences could also be simply related to $3 \mathrm{D}$ reconstruction from scanners since their degree of accuracy is equal to $0.4 \mathrm{~mm}$ or to the layer thickness of the $3 \mathrm{D}$ printing or both. Considering these parameters, an accuracy of $0.2 \mathrm{~mm}$ seems reasonable from a surgical standpoint.

Therefore, the use of the hydrogen peroxide lowtemperature sterilization for sterilization of 3D printed objects in PLA and PETG is strongly recommended.

Finally, in this study, a genioplasty guide was used as a reference object but this sterilization technique can be extrapolated to any other 3D printed object for medical purposes. This technique has successfully been tested for the sterilization of other medical objects (e.g.: the anatomical model of mandible), and no deformation of the 3D-printed object was observed after $3 \mathrm{D}$ printing and after sterilization.

\section{CONCLUSION}

Steam sterilization is not suitable for the PLA and PETG 3D-printing material, because other sterilization methods were excluded for different reasons. And because sterilization is mandatory for the use of 3D-printing medical objects in the operating room, a study was conducted to evaluate the morphological effect of hydrogen peroxide sterilization on a surgical genioplasty guide 3D-printed with PLA and PETG.

This one concludes that the morphological deformations induced by the hydrogen peroxide sterilization are sub millimeter and compatible with surgical use. The hydrogen peroxide sterilization is, therefore, an alternative avoiding the deformation of 3D-printed objects from PLA and PETG during their sterilization with steam sterilization (autoclave).

To the best of our knowledge, this is the first study about the morphologic deformation of 3D-printed objects in PLA and PETG for medical use after sterilization.

\section{LIST OF ABBREVIATIONS}

$\begin{array}{lll}\text { FDM } & = & \text { Fused-Deposition-Modeling } \\ \text { PLA } & = & \text { Polylactic Acid } \\ \text { PETG } & = & \text { Polyethylene Perephthalate Glycol } \\ \text { L-LA } & = & \text { L-Lactide } \\ \text { D-LA } & = & \text { D-Lactide }\end{array}$

\section{ETHICS APPROVAL AND CONSENT TO PARTICIPATE}

This study received the approval of the Ethics Committee of Erasme Hospital, Université Libre de Bruxelles, Brussels, Belgium under the reference: SRB_201808_171. 


\section{HUMAN AND ANIMAL RIGHTS}

No animals/humans were used in the study that are the basis of this research.

\section{CONSENT FOR PUBLICATION}

Not applicable.

\section{AVAILABILITY OF DATA AND MATERIAL}

The data that support the findings of this study are available from corresponding author ( $\mathrm{O}$. Oth) upon reasonable request.

\section{FUNDING}

Dr. Olivier Oth received a financial grant of the direction Board of Erasme Hospital to conduct this study (Grant No. 2018/06).

\section{CONFLICT OF INTEREST}

The authors declare no conflict of interest, financial or otherwise.

\section{ACKNOWLEDGEMENTS}

We sincerely thank Charline Maertens de Noordhout for her help in producing statistical data. We also sincerely thank Prof. Stéphane Louryan for his help in producing radiological data.

\section{REFERENCES}

[1] Scolozzi P. Computer-Aided Design and Computer-Aided Modeling (CAD/CAM) generated surgical splints, cutting guides and custommade implants: Which indications in orthognathic surgery? Rev Stomatol Chir Maxillofac Chir Orale 2015; 116(6): 343-9. [http://dx.doi.org/10.1016/j.revsto.2015.09.005] [PMID: 26598243]

[2] Wallace CA. New developments in disinfection and sterilization. Am J Infect Control 2016; 44(5)(Suppl.): e23-7.

[http://dx.doi.org/10.1016/j.ajic.2016.02.022] [PMID: 27131131]

[3] Chia HN, Wu BM. Recent advances in 3D printing of biomaterials. J Biol Engin 2015; 9: 4 .

[4] Harrell CR, Djonov V, Fellabaum C, Volarevic V. Risks of using sterilization by gamma radiation: The other side of the coin. Int J Med Sci 2018; 15(3): 274-9.

[http://dx.doi.org/10.7150/ijms.22644] [PMID: 29483819]

[5] Modjarrad K, Ebnesajjad S, Eds. Handbook of polymer applications in medicine and medical devices. Plastics design library Oxford; San Diego, CA: William Andrew; 2014; p. 354.

[6] Jacobs P, Kowatsch R. Sterrad Sterilization System: A new technology for instrument sterilization. Endosc Surg Allied Technol 1993; 1(1): 57-8.

[PMID: 8050015]

[7] Kyi MS, Holton J, Ridgway GL. Assessment of the efficacy of a low temperature hydrogen peroxide gas plasma sterilization system. J Hosp Infect 1995; 31(4): 275-84

[http://dx.doi.org/10.1016/0195-6701(95)90206-6] [PMID: 8926377]

[8] Shaheen E, Alhelwani A, Van De Casteele E, Politis C, Jacobs R. Evaluation of dimensional changes of $3 \mathrm{D}$ printed models after sterilization: A pilot study. Open Dent J 2018; 12(1): 72-9. [http://dx.doi.org/10.2174/1874210601812010072] [PMID: 29492172]

[9] Kozakiewicz M, Szymor P, Olszewski R. Cytotoxicity of threedimensional paper-based models from a three-dimensional paperbased printer. NEMESIS 2018; 3(1): 15 .

[http://dx.doi.org/10.14428/nemesis.v3i1.3883]

[10] San Miguel Moragas J, Oth O, Büttner M, Mommaerts MY. A systematic review on soft-to-hard tissue ratios in orthognathic surgery part II: Chin procedures. J Craniomaxillofac Surg 2015; 43(8): 1530-40.

[http://dx.doi.org/10.1016/j.jcms.2015.07.032] [PMID: 26321067]

[11] 3-dimensional printing and bio-based materials in global health. $1^{\text {st }}$ ed. New York, NY: Springer Berlin Heidelberg 2017; p. 125.

[12] Boursier J-F, Fournet A, Bassanino J, Manassero M, Bedu A-S, Leperlier D. Reproducibility, accuracy and effect of autoclave sterilization on a thermoplastic three-dimensional model printed by a desktop fused deposition modelling three-dimensional printer. Vet Comp Orthop Traumatol 2018; 31(6): 422-30.

[http://dx.doi.org/10.1055/s-0038-1668113] [PMID: 30300914]

[13] taulman3d.com/guidelne-spec.html

\section{C) 2019 Oth et al.}

This is an open access article distributed under the terms of the Creative Commons Attribution 4.0 International Public License (CC-BY 4.0), a copy of which is available at: https://creativecommons.org/licenses/by/4.0/legalcode. This license permits unrestricted use, distribution, and reproduction in any medium, provided the original author and source are credited. 